\title{
Electrochemical co-detection of Heavy Metals in Astragalus Membranaceus by Anodic Stripping Voltammetry
}

Ying Meng ${ }^{1,2}$, Dandan Kong ${ }^{2}$, Rong Wang ${ }^{2,3}$, Weijun Kong ${ }^{2}$, Zhuowen Fan ${ }^{1, *}$, Yufeng Huang ${ }^{4}$, Meihua Yang $^{2 *}$

${ }^{1}$ Department of Pharmaceutical Analysis, Heilongjiang University of Chinese Medicine, Harbin 150040, P.R. China

${ }^{2}$ Key Laboratory of Bioactive Substances and Resources Utilization of Chinese Herbal Medicine, Ministry of Education, Institute of Medicinal Plant Development, Chinese Academy of Medical

Sciences \& Peking Union Medical College, Beijing 100193, P.R. China

${ }^{3}$ College of Traditional Chinese Medicine, Jilin Agricultural University, Changchun 130118, P.

R.China

${ }^{4}$ Shanghai Academy of Traditional Chinese Medcine, Shaihai 201203, P. R.China

*E-mail: Fanzw89@163.com, yangmeihua15@hotmail.com

doi: $10.20964 / 2017.09 .19$

Received: 29 April 2017 / Accepted: 3 July 2017 / Published: 13 August 2017

Astragalus membranaceus, as an important medicinal herb, is widely used all over the world. But, the presence of toxic heavy metals in herbal chains due to the rapid industrialization possesses a serious threat on human health. For rapid screening the positive samples in medicinal herbs, an environmentfriendly strategy is reported for the determination of heavy metals by using the square wave anodic stripping voltammetry method. The method showed good selectivity, linearity, recovery and precision. It is demonstrated that the intensity of the anodic peak at $-0.87 \mathrm{~V},-0.61 \mathrm{~V}$ and $-0.24 \mathrm{~V}$ is proportional $\left(\mathrm{R}^{2}=0.9978,0.9805,0.9870\right)$ to the concentration of $\mathrm{Cd}^{2+}$ in the electrolyte over the range of 0.01 $0.10 \mu \mathrm{g} \cdot \mathrm{mL}^{-1}$, and $\mathrm{Pb}^{2+}, \mathrm{Cu}^{2+}$ in the range of $0.10-1.00 \mu \mathrm{g} \cdot \mathrm{mL}^{-1}$. The proposed method has been successfully applied to the determination of the three heavy metal ions in Astragalus membranaceus samples with satisfactory recoveries of 88.00-110.00\%. Meanwhile, the detection limits achieved $0.0010,0.0007$ and $0.0028 \mu \mathrm{g} \cdot \mathrm{mL}^{-1}$ for $\mathrm{Cd}^{2+}, \mathrm{Pb}^{2+}$ and $\mathrm{Cu}^{2+}$, respectively, which are much lower than the guideline values in herbs given by the Chinese pharmacopoeia. Real sample analysis of $\mathrm{Cd}^{2+}, \mathrm{Pb}^{2+}$ and $\mathrm{Cu}^{2+}$ in Astragalus membranaceus by the electrochemical method of anodic stripping voltammetry has demonstrated that the proposed method can be applied in rapid screening the positive samples of Astragalus membranaceus.

Keywords: Rapid screening, Heavy metal, Astragalus membranaceus, Micromorphologies, Electroanalysis 


\section{FULL TEXT}

(C) 2017 The Authors. Published by ESG (www.electrochemsci.org). This article is an open access article distributed under the terms and conditions of the Creative Commons Attribution license (http://creativecommons.org/licenses/by/4.0/). 